\title{
7. Car sharing for older adults in Oslo: practices, needs and preferences
}

\section{Tanu Priya Uteng}

\subsection{INTRODUCTION}

The re-densification project, popularly discussed under conceptual framing of transit-oriented development (Knowles, 2012; Pojani and Stead, 2014), has been adopted in Norway as a means to combat climate change. This strategy is coupled with a defined aim of reducing any increase in vehicle kilometres by private vehicles and shifting the entire bulk of future transport on sustainable modes such as walking, bicycling and public transport. One of the plug-in elements emerging in this narrative comprises the car sharing (CS) solution, which shifts the car-based private mobility from ownership to service use, and from regular to intermittent, needs-based use. A structured analysis of 137 papers on CS reveals that though CS has been analysed through different lenses - business models, customer validation, operational details, modelling, and so on - the topic of travel behaviour of older adults and CS remains unexplored (Ferrero et al., 2018).

This chapter focuses on the possibilities and problems related to CS in Oslo for the population segment of $65+$, building on the conceptual framing of social practice theory. The idea is, firstly, to show that the persistent problem ${ }^{1}$ of car driving is embedded in the practices of this demographic group; and secondly, to highlight how CS may be inserted in their travel behaviour. The chapter proceeds with a brief literature review and the theoretical framework, followed by an overview of the Norwegian active ageing agenda, population projection and spatial distribution of Oslo's 65+ population. Section 7.3 presents the background of this study, while the data and analyses are presented in sections 7.4 and 7.5. The chapter concludes with some thoughts on future policy interventions and research work in section 7.6. 


\subsection{LITERATURE REVIEW}

\subsubsection{Older Adults' Travel Behaviour}

Studies, both in and outside Norway, confirm that age and travel behaviour exhibit strong correlations, and car usage has become a routinized practice for the 65+ age group (Hjorthol et al., 2010; Scheiner, 2006). Further, urban areas in Norway exhibit the following tendencies (Saeterøy, 2018; Priya Uteng, 2012; Hjorthol et al., 2011):

1. Men aged 35-45 are the most eager drivers, but the average number of daily car trips has been declining.

2. Simultaneously, for middle-aged men (45-65-year-olds), there has been an increase in average number of daily car trips.

3. This trend is even stronger for $65+$ years where an accelerating increase in the number of daily car trips has been recorded.

Additionally, a recent study (Hjorteset and Böcker, 2020) exploring the intentions to participate in CS in the nine largest urban areas of Norway revealed that older adults were less likely to participate in car sharing in the near future. The lack of intention to participate in car sharing is explained by the fact that this group is less financially conscious compared to younger people. Analysing the patterns of current CS membership further revealed that older members more often owned a private car, thereby making them less likely to be members of car sharing platforms (ibid.). Previous literature does indicate that CS, so far, has the highest uptake among the younger generations (Prieto et al., 2017; Priya Uteng and Farstad, 2020).

It might be tempting to assume that the older adults are more reluctant to adopt new modes of transport, particularly modes embedded in technology such as CS. Such blanket statements have proven to be unhelpful and have largely been refuted (Olson et al., 2011). The complexity of the population's transport needs, along with its social systems, is important to keep in mind when analysing and discussing future pathways. In line with Kent and Dowling (2013), the guiding principle is understanding the routines, age-based necessities, circularity and preferences, which can be approached through employing the conceptual framing of social practice theory.

\subsubsection{Social Practice Theory (SPT)}

Social Practice Theory (SPT) states that a practice is a routinized behaviour consisting of a set of interconnected elements: materials, skills and meaning (Reckwitz, 2002; Pantzar and Shove, 2010). A central tenet is that a practice 
can be understood both as a performance through the observable behaviour of individuals, and as an entity which emerges through socially shared ideas and meanings, knowledge, skills, materials and infrastructures (Wilson, 2015).

Pantzar and Shove (2010) argue that innovation is a continuous process that persists through the reproduction of practices, and this reproduction takes place through a collusion of managers, manufacturers and consumers who make and sustain connections between the defining elements of practices. They raise some pertinent questions for the case of CS: 'how can managers and manufacturers institutionalise practices that require consumption of the things they make? Is there any fundamental difference in the role of "lead" and "ordinary" users in generating and sustaining innovations in practice?' (ibid: 441).

Framing innovation in the lingo of SPT, Wilson $(2015$, p. 10) borrows Shove and Pantzar's (2005) framing that 'Innovations in practice are about making and breaking links between elements of material, image and skill. We suggest that such linkages are always local and that what looks like the "diffusion" of practice is better understood as its successive (re)invention'. These successive (re)inventions typically take place at the macro and micro levels, which Jensen (2014) frames as 'staging mobilities'. For CS, the macro level or staging from above entails the actions of planners, engineers, politicians and information technology companies designing smart solutions; while staging from below consists of performing mobilities. The following questions can be further analysed to understand the meaning and embodied performances of CS by the older adults population:

- How is CS being staged from below?

- How can we promote CS in the $65+$ age group?

\subsection{BACKGROUND}

\subsubsection{Active Ageing Agenda of Norway}

Norway's development agendas are rooted in the welfare model. Consequently, ageing is also framed in the welfare format, and is rooted in the financial and social sector. The financial repercussions of an expanding older adult population are evident through increasing old-age dependency ratios, imbalances in net tax payments, downward trends in average pension age, and a particularly Norwegian indicator known as 'shark jaw', revealing the growing gap between increasing pension expenditure and decreasing oil revenues (Foss, 2003; Ervik and Helgøy, 2013). Given these framings, keeping the older adults in paid employment for an extended period of time has been emphasized. 
As a primary response, the social framing of the ageing agenda was designed to support the economic underpinnings:

if people are kept in work, supported in developing their competences and provided with interesting work tasks, then they will develop, grow and remain in good health. Work gives the individual challenges and opportunities needed for learning. It provides a person with an opportunity for social contact and inclusion. The key problem at the individual level was social exclusion. (Ervik and Helgøy, 2013, p. 189)

A secondary response is evident in redesigning of the health and care services to enable older adults to stay as long as possible in their private residences. The public social services wing of the municipality provides personal care services to dependent, older people to support them live autonomously, when independent living becomes an issue.

Effectively, there are three dimensions on which the Norwegian ageing agenda is formulated: pension, extended employment and care services (Strand, 2018). Discussions related to long term solutions and supportive environments focus primarily on these three domains. This framing, however, fails to appreciate the broader conception of civic participation and its interlocking with spatiality - location, daily travel, activity participation, and so on - remains fuzzy. Additionally, the third pillar of sustainability, environment, is absent in discussions on active ageing. The two most prominent responses to the Norwegian social inclusion approach, bearing significant environmental consequences, are evident in the following trends (Priya Uteng, 2012; Saeterøy, 2018):

1. Relocation of the older adults to apartment blocks built near the transit nodes and central locations.

2. Though these relocated older adults have good public transport connectivity, their mobility remains car-based.

\subsubsection{Population Projection for Oslo}

According to Statistics Norway's projections, the share of Oslo's 65+ population will grow from 15 per cent in 2016 to 20 per cent by 2040. Another facet of Oslo's ageing population will be evident by 2028 when 'established workers' (40-64 age group) will overtake the 'young workers' (25-39 age group), and the young workers' growth trajectory is also projected to stagnate around the same year. Contrary to the current promoters and active users of CS, the elder age groups will constitute a larger share of Oslo's overall population by 2040, thereby exerting a higher influence on future mobility. 


\subsubsection{Ageing and Residential Pattern in Oslo}

In order to map the relationship between residential location of older adults and distance to the nearest local centre (according to Statistics Norway's definition of local centres), we plotted the distance between the centre and residential location of the different age groups for 2014. Distance plotting highlighted that the average distance between a local centre and the residential location of the different age groups drops by approximately 3 metres with each successive year of ageing as we progress from the age of 50 to 90 . This synchronizes with observations of several Norwegian researchers and planners pointing towards a general tendency of older adults to shift closer to the local centres in urban areas. A detailed analysis of this emerging pattern at the national level has not been undertaken in this research.

\subsection{DATA}

This chapter employs a mixed-methods approach, where the qualitative data constitutes of in-depth personal interviews of households conducted in Oslo between May 2017 and February 2018. These interviews were held at the households' residences, lasting about 60-90 minutes each, covering a number of aspects related to the households' daily mobility practices, with a particular focus on CS. The interviews were conducted with households subscribing to one or multiple CS platforms in Oslo. Of the 39 interviewed households, only the following three households qualified to represent the older adults. They were extracted to reflect the needs and preferences of the older adults in relation to CS's potential for addressing their daily mobility needs.

1. HH_A. 65-year-old single woman, living independently. CS membership: Hertz bilpool (business-to-consumer model, B2C).

2. HH_B. 60-year-old woman, living with partner. CS membership: Bilkollektivet (cooperative model).

3. HH_C. 50- and 52-year-old couple. CS membership: Bilkollektivet (cooperative model), Nabobil (peer-to-peer model, P2P), Hertz (business-to-consumer model, B2C), and others.

The household interviews were followed by an online questionnaire survey, distributed in November-December 2017, among members of different CS platforms. The total of number of respondents from Oslo was 2030, out of which 70 were in the age category of $65+$. 


\subsubsection{Survey Format}

Data collected from both surveys were framed in the narrative of SPT, taking materiality, skills and meanings associated with CS as departure points, and included the following three dimensions.

First, motives for CS. To capture the distinction between instrumental, normative, affective and symbolic dimensions (Jensen, 1999; Noppers et al., 2014; Steg, 2005) on both starting and continuing with CS, we applied a minimal set of questions, assessed on a Likert-scale of 1 to 7 . For the instrumental dimension, we asked to respond on: 'I can save money with CS' and 'CS is more practical than owning a car'. For symbolic motives, we asked for responses to: 'CS fits with my identity' and 'I identify as a motorist'. To capture more normative types of motives, the following were posed: 'I wish to travel in environmentally friendly ways' and ' $\mathrm{CS}$ is more social and inclusive'. The same questions were framed as open-ended questions in the face-to-face interviews.

Second, car ownership and sharing history. Given that the daily mobility of the older adults is primarily car-based, and their history as car owners and usage of other modes of sharing may play an important role in influencing their choices in opting for CS, we asked the following two questions: whether they or someone in their household previously owned a private car and/or whether they had one in the household; and whether they had used CS or other sharing platforms such as Airbnb before and the extent of usage.

Third, material and social infrastructure. To capture the material dimension, we asked the following questions: 'How good is access to parking where you live?' and 'Approximately what is the distance to the closest public transport stop?'

\subsection{ANALYSIS}

\subsubsection{Face-to-Face Interviews}

Table 7.1 presents the most vital elements extracted from interviews with the three households shedding light on issues related to adoption and retention of CS for the older adults. All three households had previously been car owners, decided to give up car ownership and opted for CS instead.

\section{The materiality of cars and CS}

The interviews reveal that there exists a willingness to forgo car-based mobility, as owning and maintaining a car is considered to be a hassle. Apart from the set of activities involved in maintaining a car, another major hassle involved parking issues. The decision to forgo car ownership was simulta- 


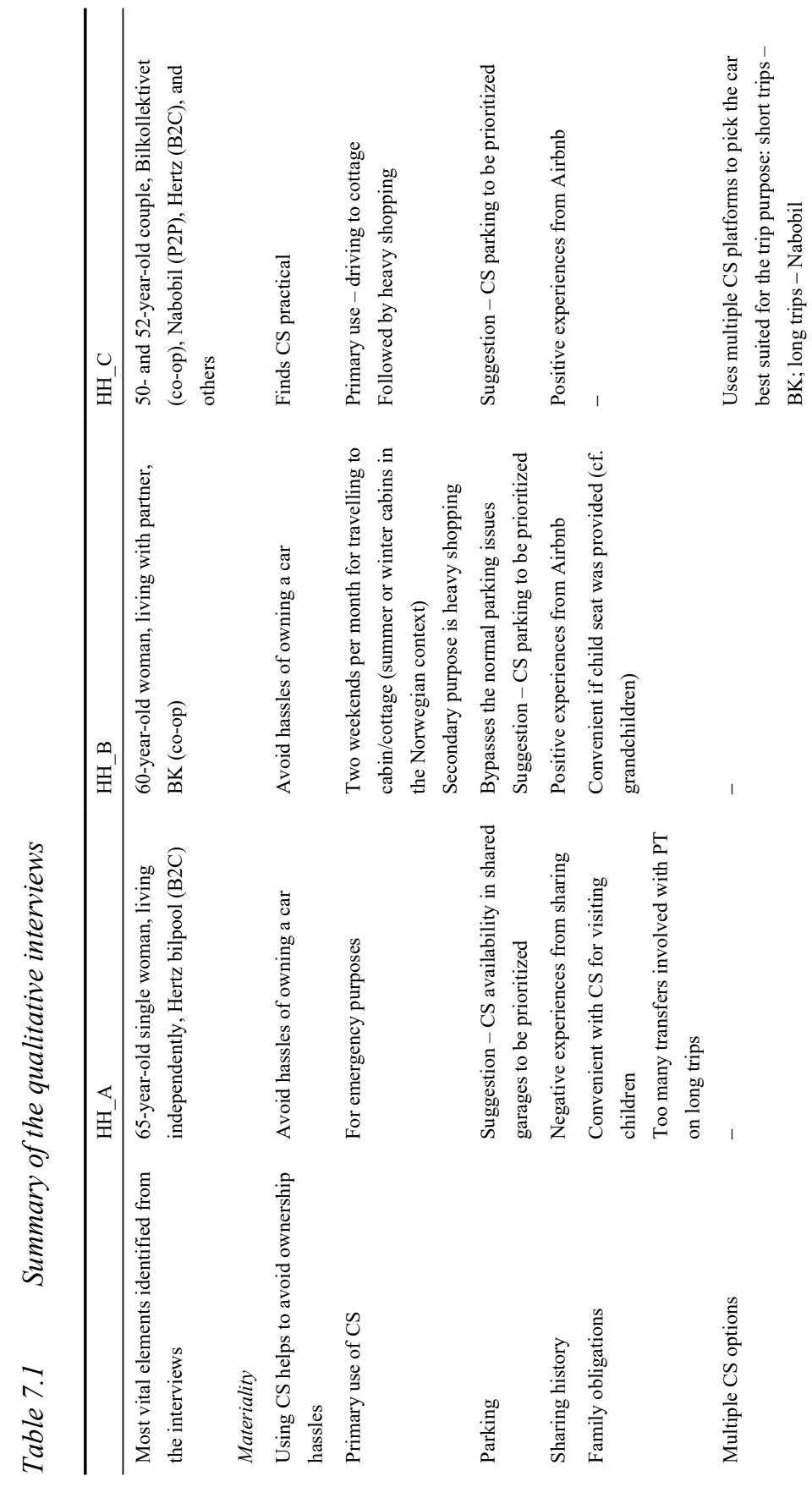




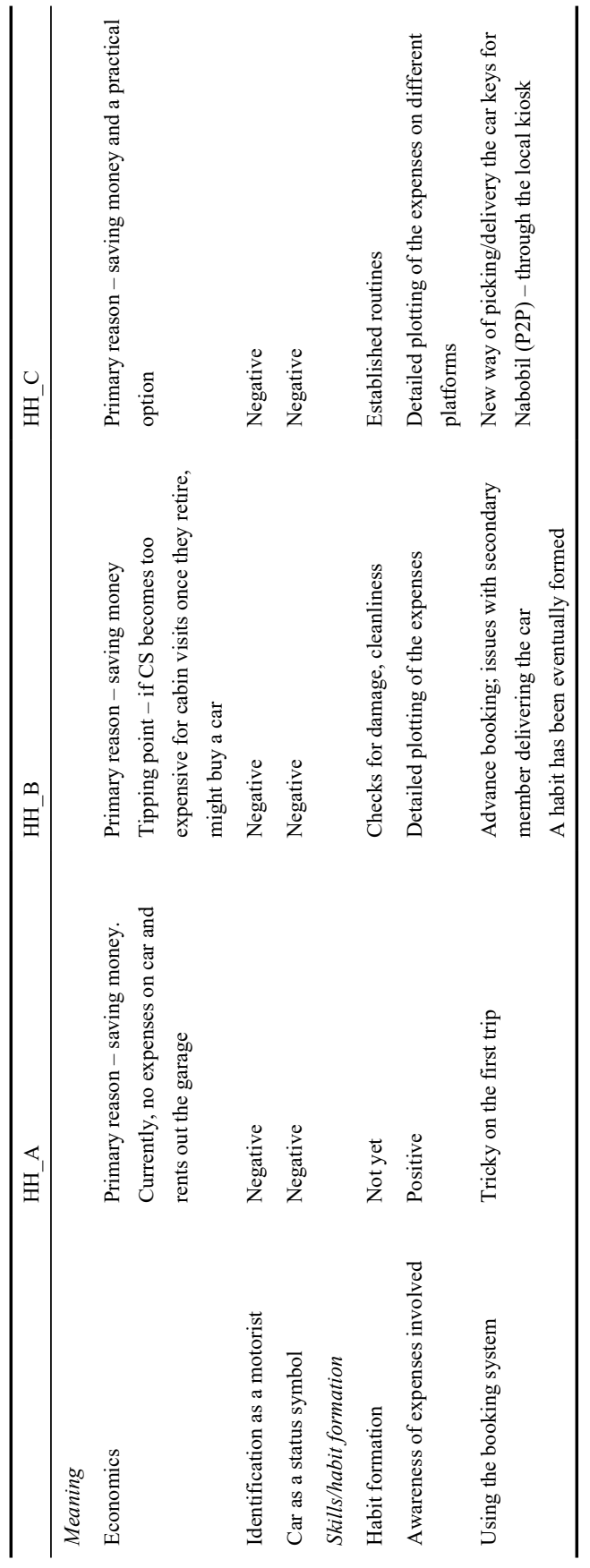


neously dependent on high accessibility levels to basic facilities afforded to the respondents by virtue of living in high-density neighbourhoods. All three respondents lived in areas well connected by public transport, bicycling and walking, and the residential location allowed for easy access to the CS pick-up points.

CS is used primarily for accessing cabins, often located in areas difficult to reach with conventional public transport. The frequency of visiting cabins seems to increase with age, which becomes almost a primary trip, with at least bi-monthly frequency, at the onset of retired life. Both economics of charges (per hour versus per day) and the type of available car play a vital role here. The seasoned car sharers have developed schematics to calculate the costs of cabin trips on different platforms and decide accordingly. The cooperative model of CS is typically preferred for short-distance, intra-city trips; while peer-to-peer ( $\mathrm{P} 2 \mathrm{P})$ gets precedence for long-distance trips both due to pricing and the array of cars available on $\mathrm{P} 2 \mathrm{P}$.

Dedicated parking in the neighbourhood or an easy access to shared cars emerged as a single most vital element in need of immediate attention and correction, according to the respondents.

\section{Meanings associated with cars and CS}

The car itself seems to have lost its vantage standpoint as a status symbol or harbinger of happiness, and for the seasoned users, CS is fast replacing the traditional meanings of freedom associated with private ownership of cars. HH_B's partner responded as following:

I wonder if you actually need to turn the problem upside down and ask - why use a car? It is absurd that people continue to possess and use a car in their daily lives. Car has absolutely no meaning in this day and age as anything other than a means to an end. And for that, we don't need to possess it really!

\section{Skills associated with cars and CS}

The households which had lived abroad in countries where CS is a normalized routine were adept at using the system, underlining a most important element: routinized practices. $\mathrm{HH}_{-} \mathrm{A}$, for example, had trouble in using the app-based lock system and opening the parking garage, which she categorized as being tricky and irritating. This ceased to bother her once she had figured out the mechanics of the app-based system. Similarly, HH_C has come to an original solution of picking up and dropping off car keys at the local kiosk, bypassing the need to fix meetings with the car owner for a regular P2P arrangement. 


\subsubsection{Quantitative Survey Analyses}

As Figure 7.1 demonstrates, even for the older adults who are CS members, there is a dominance of private car usage for different trip purposes. This is surprising, since close to 80 per cent of the older respondents live near public transport (PT) stations connected to a high-frequency network. A comparison of these two facets - high car dependence (private car usage) and simultaneously having good access to PT - reveal the element of practice where private car usage has become a routinized practice for the $65+$ population.

Figure 7.2 shows scores on a scale of 1 'to a low extent', to 7 'to a great extent'. It is evident that the older adults have a constricted association with CS. They do not rank CS high on any of the elements, which could be an explanatory factor behind their high dependence on private cars and low uptake of CS. It seems that the older adults are passive members of CS schemes, or they participate in the peer-to-peer scheme to rent out their car instead of curtailing their car dependency. The sample size for the peer-to-peer members was too small to comment specifically on this issue, and can be explored in future studies.

From a practice perspective, the interviews revealed that ease of access to shared cars through fixed parking slots in the vicinity is an essential aspect to enhance the uptake of CS among older adults. A similar line of enquiry was pursued in the questionnaire survey. The results highlight that dedicated parking space received the highest scores. Further, though this group followed the same pattern as the other age groups in their ranking of the preferred changes to the CS system, their web of responses remained constricted.

We were curious to explore the positionality of the car per se in terms of both materiality and meanings attached to it. What emerges is a confusing picture. The older adults, who have so far displayed a strong propensity and preference for car usage, displayed a rather distanced position from the car. They gave high scores to the car being an uneconomical choice, and low on their own interest and identification with the car. Simultaneously, they are actively seeking to live in urban areas.

Considering these contradictory findings, one could assume that there are certain deficiencies in the system itself which have so far failed to capture the needs of the older adults. We therefore asked them to score the following elements regarding ease of using the organizational interfaces of CS (scored on a scale of 1 to 7 , where 1 is 'completely disagree'): 'I feel confident and safe while using the booking-system for car sharing and I feel confident and safe in picking and delivering the car'. The differences in scores given by the different age groups ( $\leq 24,25-39,40-64$ and $65+)$ were statistically significant ( $p<0.001$ chi-sq), and mean score for feeling confident and safe in using the system was lowest for the $65+$ population. It is evident that the older adults 


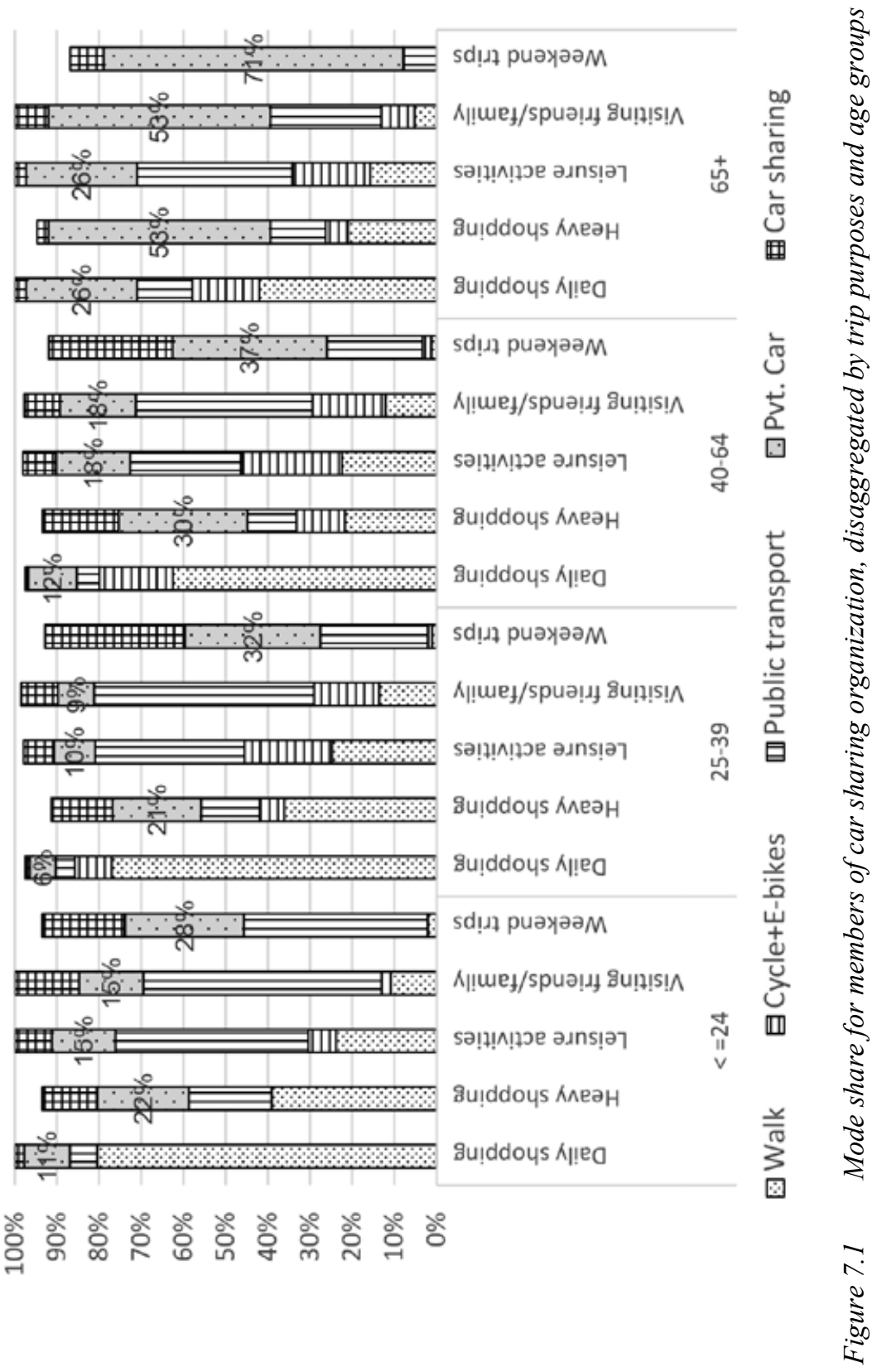




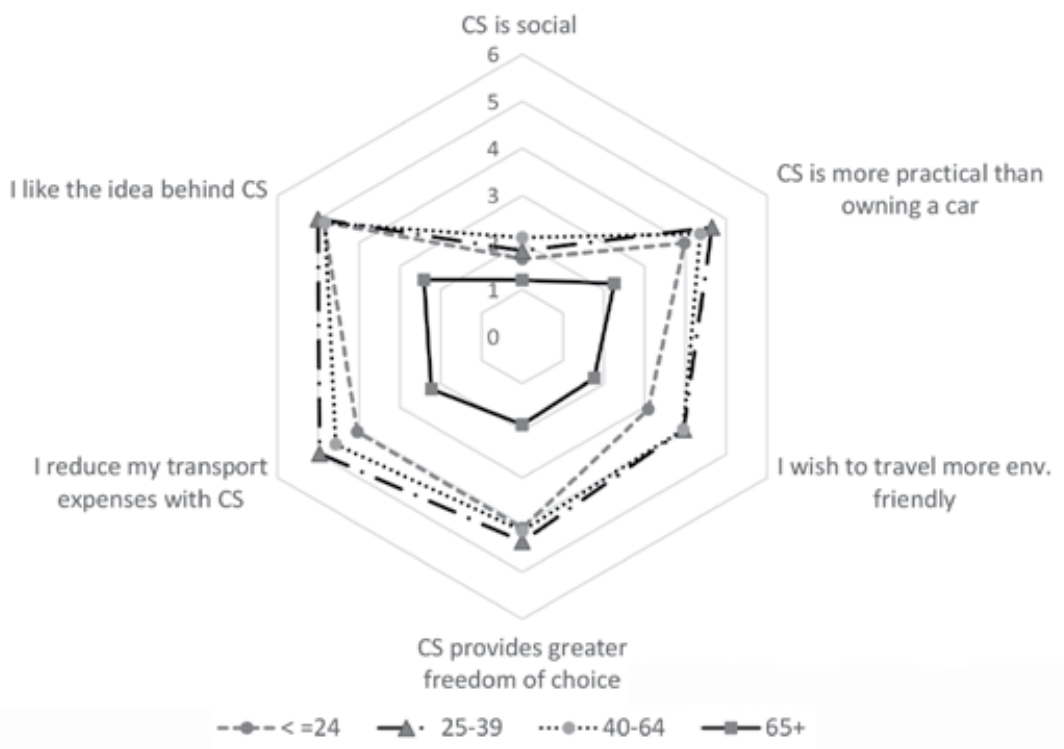

Figure 7.2 Meanings attached to CS by the members of CS organizations need special assistance in using the CS booking, picking and delivering systems.

\subsection{CONCLUSION AND RECOMMENDATIONS}

The mutual overlaps and occasional interlocking of the topic of active ageing and CS has so far not been explored in research studies. The preliminary findings presented in this chapter highlight that it is a good idea to integrate CS to ageing strategies, as a replacement for private car ownership. This will not only ensure a more active lifestyle for the older adults despite less car use, but holds the potential to reduce the fleet of cars on the streets, and thus reduce requirements for facilitating car-based traffic. Given the population projections for the entire Western world, substantial gains can be harnessed from subsequent freed-up space for active modes and a renewed framing of the urban mobility and active ageing agenda.

Zooming in to the case at hand, the Norwegian active ageing agenda remains preoccupied with the economics of ageing, evident through focus on flexible pension and health reforms to keep older adults in working life for a longer stretch. Social inclusion is also being interpreted in terms of prolonged 
working life. Ageing in their own residence with state-supported assistance as and when needed is the established rule, as a result of which a vast majority of the older adults are shifting to apartments near transit nodes and hubs with a dense concentration of easily accessible basic facilities. Simultaneously, daily mobility of the older adults is largely car-based. Given that the 65+ population is a fast-growing age group, and when these developments are seen in light of Norway's objective of focusing future traffic growth on sustainable modes, there exists a gap unaddressed by the active ageing agenda.

CS, a mode which is integrated and dependent on a high usage of walking, cycling and public transport in daily routines, provides a viable option to shift older adults from car-based mobility to more active forms. However, CS has not been discussed in mapping future mobility of older adults. The reduced effort costs of using PT in living close to transport hubs seems to be offset by this group's inability to shed their car-based mobility. This leads to a suboptimum usage of the convenience and financial benefits that transport hubs offer. Alternatively, as a starting point, CS needs to target the older adults as an important and untapped consumer group, and make modifications to meet their needs and preferences.

The first step towards this end is to conduct focused surveys to understand their needs and preferences for an eventual shift to CS. A general questionnaire survey, such as that presented in this study, fails to elicit a satisfactory response rate from the older adults. Qualitative interviews revealed that CS was an attractive mode, since it facilitates independent and fast mobility whenever desired. The older adults recognize the benefits of CS, and frame it primarily in terms of convenience and economics, followed by the environmental concerns. Convenience of CS is directly dependent on provision of on-street parking for shared cars, easily accessible delivery points for station-based CS, and innovative solutions such as delivering the car keys to local kiosks for peer-to-peer services. The quantitative data analyses reveal that though the shape of preferences for the older adults and general population remain the same, the magnitude differs, implying that the current CS system is unable to cater to particular needs and preferences of this group. Future studies and CS projects could use the framing of experimentation and interventions to explore possibilities of increased CS for the older adults. These studies should further also adopt a combination of 'travel demand management' and 'lifestyle' approach to explore the openings in an everyday life centred around walking, cycling and PT, and then focus on whether and how CS can be adapted to daily routines to facilitate new mobility habits. 


\section{NOTE}

1. See Schuitmaker-Warnaar (2012) for a discussion on persistent problems, formulations similar to the 'wicked problem' developed by Rittel and Webber (1973), and the 'ill-structured problem' discussed by Hisschemöller and Hoppe (1995).

\section{REFERENCES}

Ervik, R., and Helgøy, I. (2013). Policy paradigms and ideological frames in British and Norwegian ageing policy processes. In: R. Ervik and T.S. Lindén (eds), The Making of Ageing Policy: Theory and Practice in Europe. Cheltenham, UK and Northampton, MA, USA: Edward Elgar Publishing, pp. 179-204.

Ferrero, F., Perboli, G., Rosano, M., and Vesco, A. (2018). Car-sharing services: an annotated review. Sustainable Cities and Society, 37, 501-518.

Foss, P.K. (2003). While we wait for the Pension Commission - why is it necessary to expedite pensions reform? Lecture delivered by finance minister Per Kristian Foss, Bondevik II government on 08.02.2003. Oslo: Ministry of Finance.

Hisschemöller, M., and Hoppe, R. (1995). Coping with intractable controversies: the case for problem structuring in policy design and analysis. Knowledge Technology Policy, 8, 40-60.

Hjorteset, M.A., and Böcker, L. (2020). Car sharing in Norwegian urban areas: examining interest, intention and the decision to enroll. Transportation Research Part D: Transport and Environment, 84, 102322.

Hjorthol, R.J., Levin, L., and Siren, A. (2010). Mobility in different generations of older persons: the development of daily travel in different cohorts in Denmark, Norway and Sweden. Journal of Transport Geography, 18, 624-633.

Hjorthol, R., Nordbakke, S., Vågane, L., Levin, L., Sirén, A., and Ulleberg, P. (2011). Mobility and welfare of older people - development, travel needs and measures. Report no. 1179/2011. Oslo: Institute of Transport Economics.

Jensen, M. (1999), Passion and heart in transport - a sociological analysis on transport behavior. Transport Policy, 6, 19-33.

Jensen, O.B. (2014). Designing Mobilities. London: Routledge.

Kent, J.L., and Dowling, R. (2013). Puncturing automobility? Carsharing practices. Journal of Transport Geography, 32, 86-92.

Knowles, R.D. (2012). Transit oriented development in Copenhagen, Denmark: from the finger plan to Ørestad. Journal of Transport Geography, 22, 251-261.

Noppers, E.H., Keizer, K., Bolderdijk, J.W., and Steg, L. (2014). The adoption of sustainable innovations: driven by symbolic and environmental motives. Global Environmental Change, 25, 52-62.

Olson, K.E., O'Brien, M.A., Rogers, W.A., and Charness, N. (2011). Diffusion of technology: frequency of use for younger and older adults. Ageing International, $36(1), 123-145$.

Pantzar, M. and Shove, E. (2010). Understanding innovation in practice: a discussion of the production and re-production of Nordic Walking, Technology Analysis and Strategic Management, 22(4), 447-461.

Pojani, D., and Stead, D. (2014). Dutch planning policy: the resurgence of TOD. Land Use Policy, 41, 357-367. 
Prieto, M., Baltas, G., and Stan, V. (2017) Car sharing adoption intention in urban areas: what are the key sociodemographic drivers? Transportation Research Part A: Policy and Practice, 101, 218-227.

Priya Uteng, T. (2012) Transport-related social exclusion: incorporating imperatives of age and gender in the transport planning processes. $\mathrm{PhD}$ thesis, Trondheim: NTNU.

Priya Uteng, T., and Farstad, E. (2020) Car sharing, life course and young people's approach to daily mobilities: a dialogue between qualitative and quantitative research findings. In: J. Scheiner and H. Rau (eds), Mobility Across the Life Course: A Dialogue between Qualitative and Quantitative Research Approaches. Cheltenham, UK and Northampton, MA, USA: Edward Elgar Publishing, pp. 152-171.

Reckwitz, A. (2002). Toward a theory of social practices: a development in culturalist theorizing. European Journal of Social Theory, 5, 243-263.

Rittel, H.W.J., and Webber, M.M. (1973). Dilemmas in a general theory of planning. Policy Science, 4, 155-169.

Saeterøy, M.J. (2018). Projecting sustainable mobility scenarios for Oslo towards 2040: the potential of car-sharing, ridesharing and cycling. Master's thesis in Entrepreneurship, Innovation and Society. Trondheim: NTNU.

Scheiner, J. (2006). Does the car make elderly people happy and mobile? Settlement structures, car availability and leisure mobility of the elderly. European Journal of Transportation and Infrastructure Research, 6, 151-172.

Schuitmaker-Warnaar, T.J. (2012). Identifying and unravelling persistent problems. Technological Forecasting and Social Change, 79(6), 1021-1031.

Shove, E., and Pantzar, M. (2005). Consumers, producers and practices: understanding the invention and reinvention of Nordic Walking. Journal of Consumer Culture, $5(1), 43-64$.

Steg, L. (2005), Car use: lust and must. Instrumental, symbolic and affective motives for car use. Transportation Research Part A Policy and Practice, 39(2-3), 147-162.

Strand, A. (2018) Norway: safe and active ageing in an inclusive welfare society. Paper presented at MIIPA meets SDG1, 31 January. New York: United Nations. https://www.unece.org/fileadmin/DAM/pau/age/Event/Presentations/Aina_Strand Norway.pdf (accessed 10 October 2020).

Wilson, P. (2015) The development of cycle commuting centres from a social practice perspective, paper presented at the Annual Cycling and Society Symposium 14-15 September. Manchester: University of Manchester and University of Salford. http:// www.cyclingandsociety.org/wp-content/uploads/2015/10/CSS2015-Paul-Wilson -Presentation.pdf (accessed 10 October 2020). 